\title{
Regionally Speaking: Cultural Leadership and Capacity Building in the Asia Pacific Region
}

\author{
Caitlin Byrne and Ruth Bereson
}

\section{Contents}

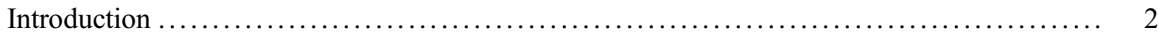

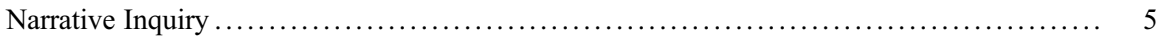

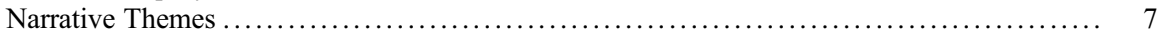

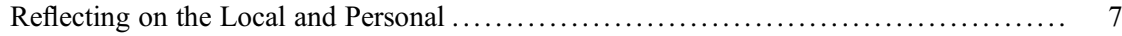

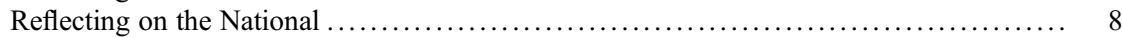

Reflecting on the Regional .............................................. 13

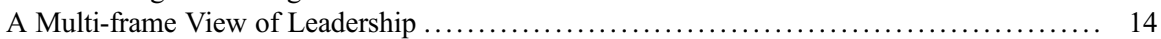

Leadership in the Political Frame .......................................... 14

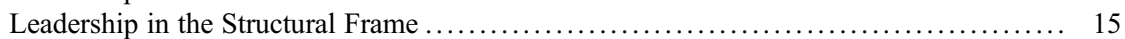

Leadership in the Social Frame ........................................... 16

Leadership in the Symbolic Frame ........................................... 16

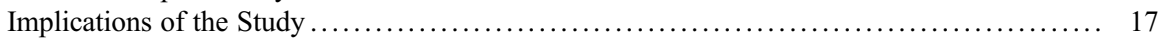

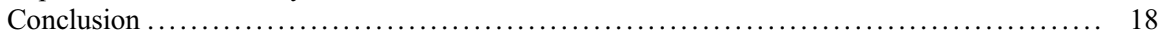

Cross-References ......................................................... 19

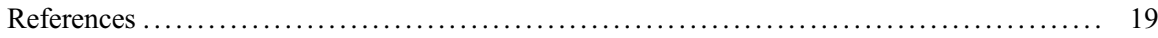

\section{Abstract}

The arts and cultural sectors are increasingly seen as holding out potential for new models of leaders and leadership. The discipline of leadership has thus become alive to the notion of drawing upon and learning from arts-based methodologies to improve practice and development. However, there remains a paucity of emphasis on leadership from and within the arts. This chapter provides an empirical account of how that can take place.

C. Byrne ( $\square)$

Griffith University, Nathan, QLD, Australia

e-mail: c.byrne@griffith.edu.au

R. Bereson

Griffith University, Mount Gravatt, QLD, Australia

e-mail: r.bereson@griffith.edu.au 
Using a narrative inquiry approach, the chapter explores the journey of a select cohort of arts practitioners from Southeast Asia and shows an emerging rich framework for leadership capacity building. In commenting on how the study evolved, the chapter provides insight into gaps in the theory and practice of leadership development within the arts.

\section{Keywords}

Arts practice $\cdot$ Leadership $\cdot$ Narrative enquiry

\section{Introduction}

Theories and practice of leadership are in need of imaginative restructuring if they are to deal with the complex events and challenges of today's world. Forms of leadership that emphasize the aesthetic dimension - that is, how individuals might experience the world as a counterpoint to rational or formulaic processes - are likely to play a significant role. Furthermore, understanding the experience of leadership not just within an organizational context but within national and regional contexts is increasingly relevant to the new realities of a dynamic, transnational world. These challenges are particularly pertinent to the contemporary "arts practitioner," often adept and increasingly expected to cross boundaries, operate within multiple domains, and engage diverse audiences in the quest for making meaning. In Arts Management studies this is described as an "Aesthetic Contract" (Pick 2009). The learnings drawn from arts practice and practitioners are of interest to contemporary leadership studies. Applying a narrative inquiry approach, we explore the journey of a select cohort of arts practitioners from Southeast Asia to understand their individual and collective experiences across multiple domains. ${ }^{1}$ What emerges is a rich framework for leadership capacity building; in which the participants became owners of the thematic journey, embodiments of their practice and narrators of their own stories, at a confluence of cultural and political discourse. It is a self-reflexive framework, which we hope might give rise to what Ladkin (2020, p. 2) calls "a different kind of wisdom, one that appreciates context, one that understands human engagement as something that cannot always be navigated with neat company policies."

The arts and cultural sectors are increasingly seen as holding out potential for new models of leaders and leadership (Asbjörnson 2007; Sutherland 2012). There is

\footnotetext{
${ }^{1}$ The study at the center of this chapter, also known as Regionally Speaking is a unique model of engagement and capacity-building designed, developed, and led by Griffith University Professors Ruth Bereson (Dean Academic, Arts Education and Law Group) and Caitlin Byrne (Director, Griffith Asia Institute). Created in 2016 to celebrate the 50th anniversary of the Association of Southeast Asian Nations (ASEAN), the project focuses on building the critical capacity and connections of emerging arts practitioners from ASEAN to deepen regional understanding and connections, promote co-operative engagement, and strengthen their collective voice as cultural advocates and leaders across the region.
} 
a natural synergy between leadership and the arts as both seek to inspire, to bring people together, to reframe and change the way people think, and to invent possibilities not previously imagined (Asbjörnson 2007, p. 22). Business management and leadership studies have become increasingly aware of the synergies, prompted in part by what Sutherland (2012, p. 25) describes as "a growing disenchantment with the traditional (rational, instrumental, economically dominated, realist oriented and 'objectively analytical) means of practice and development." The resultant turn toward "self-reflexive scrutiny" of leadership practice, particularly within executive education circles has spurred an interest in the need to engage arts-based methodologies within leadership education (Koivunen 2003; Beuchel and Antunes 2007; Garvin 2007; Houde 2007; Kets de Vries and Korotov 2007). As Asbjörnson (2007, p. 23) observes:

many personal and professional development programs emphasise the science of leadership. But the human aspect of leadership - the ability to create and sustain meaningful connections with an audience - is what really provides the foundation for effective leadership.

Ladkin and Taylor (2010) make a similar point:

...we live in a complex world which cannot be fully understood solely by reference to scientific forms of logic and sense-making. The arts, and art-based practices, provide different ways of both describing and relating to that complexity, thereby offering novel ways of responding.

The discipline of leadership has thus become alive to the notion of drawing upon and learning from arts-based methodologies to improve practice and development. A "developing community of research and literature that situates arts-based methodologies as experiential learning to improve participants' abilities in responsibly navigating the complexities of contemporary organisational contexts" has emerged alongside this emerging awareness (Sutherland 2012, p. 26; Ladkin 2010; Koivunen 2003).

While there is an emerging emphasis on the role of the arts in improving leadership practice, there remains a paucity of emphasis on leadership from and within the arts. The underpinning narratives, relationships, and networks that are inherent to the arts and cultural sectors are not necessarily harnessed or developed beyond their immediate parameters. Yet little, if any, attention is paid to the leadership role or capacity of those practitioners - the artists, arts managers, producers, curators, and critics - who direct the sector. Indeed, the general view persists, particularly from those outside the sector, that the role of the arts practitioners is simply to attract and enthuse audiences. While there is useful discussion of organizational leadership relevant to arts bodies and institutions, in our view this is insufficient to meet the demands being placed on the arts and cultural sectors in a global policy context. 
The aim of this study is to explore gaps in the theory and practice of leadership development within the arts. It seeks to identify a new model for both studying and building leadership capacity through narrative inquiry. In the study, narrative inquiry provided the primary tool for engaging the aesthetic dimension. Asking the participants to consider their journey in the arts from the personal or local, the national and regional views, allowed us to understand the leadership experience and capacity of arts practitioners from different perspectives. At the same time, the narrative process enabled a self-reflexive journey that fostered and developed the leadership capacity of the participants and offered some potential for strengthening their collective voice.

This chapter centers on the journey of a study which involved participants from Southeast Asia, conducted across several workshops. It began as a mapping exercise, the original intent of which was to map the cultural profile of ASEAN. But it became clear to us as researchers, particularly as we engaged in conversation with our participants that there was a far more textured story to uncover. While we were originally focused on the role and relevance of arts and culture in engaging diverse nations across a region, it became apparent over time that the leadership capacity of the individual practitioners shaping and driving cultural and artistic practice was of central importance. Our research team was keen to understand the nature of this capacity and how it might be developed in a way that offered a best fit for the wider role and responsibility of arts and culture in effecting global policy impact. We had encountered a problem that Daigle (2016, p. 26) aptly captures when she notes, "Time after time, their individual perspectives, backstories, and vibrancies refused to map onto traditional scientific notions of data or results." A cultural mapping exercise, or the plotting of data points on a map, could not reveal the cultural inflections or textures that we hoped to uncover. We then turned to narrative inquiry as our preferred method and leadership capacity as the focus.

The geographic context of this study is of significance. Southeast Asia is a region marked by deep diversity and dynamism, reflected by almost every measure, including geography, biodiversity, language, political organization, economies, and religious beliefs. One might argue that leadership plays an essential role in maintaining stability and order within and between communities and nations of the region. This was a point we were keen to explore. Secondly, Southeast Asia's regional institution, the Association of Southeast Asian Nations (ASEAN), has placed significant emphasis on the role of arts and culture as a mechanism for regional order and integration. This is most evident through the establishment of ASEAN's vision for a sociocultural community, and more recently through the launch of its Strategic Plan for Culture and the Arts (ASEAN Secretariat 2016a). ${ }^{2}$ Having celebrated its 50th anniversary in 2017, ASEAN offered, prima-facie, a relevant yet underexplored aspiration to develop leadership through arts and culture. The connection between

\footnotetext{
${ }^{2}$ The ASEAN Strategic Plan for Culture and the Arts 2016-2025 identifies its vision as building, "an ASEAN Socio-Cultural Community that engages and benefits the people and is inclusive, sustainable, resilient and dynamic."
} 
individual leadership and regional institution building offered a compelling model for interrogation.

It is worth noting from the outset that the study of aesthetics reflects ensuring Western philosophical traditions and frames of reference (Beardsley 1991; Guillet de Monthoux 2004; Ladkin 2018). We recognize that this raises important questions about our own approach to the research, and whether such Western traditions are appropriate frames of reference when exploring non-Western contexts. We are sensitive in particular to claims of colonialist tendencies that might arise (Blocker 2001). In responding to such claims we note that this chapter is neither a study of the philosophy of aesthetics nor a comparative study of the tradition of aesthetics as constructed across Western and non-Western contexts. A further tension arises in the range of ways that the aesthetic is understood and applied, including across various business management disciplines. We lean toward a more pragmatic understanding of the aesthetic as "a way of knowing," whereby "attending to one's own experience and sense of the situation becomes paramount" (Ladkin 2018, p. 34; see also Bereson and Guillet de Monthoux 2017).

The chapter is organized as follows. It begins with review of narrative inquiry as a tool for the qualitative study of leadership, noting its interdisciplinary relevance. The second section hones in on the common themes to emerge through participant narratives. It sheds light onto the core challenges each of the participating practitioners face as individuals within their own sector and national boundaries, and collectively within the regional construct of ASEAN, thus enabling "thick description" narrative to emerge. The third section then seeks to understand the leadership capacity of these participants as active practitioners and representatives of the Southeast Asian arts sector. Here we draw on Bolman and Deal's (2003) wellestablished multi-frame leadership approach as the basis for analysis. Mapping the narrative themes against the four adapted frames of leadership: (i) political; (ii) structural; (iii) social; and (iv) symbolic reveals a more complex leadership role for arts practitioners than might have otherwise been recognized. Finally, the paper explores the implications for leadership from the arts, and development of leadership capacity within the arts. While findings point to an intuitive capacity for arts practitioners to play a more significant leadership role in today's complex environment, they also suggest that there appear to be fundamental gaps in leadership thinking, particularly when it comes to engaging beyond one's self and sector through the political leadership frame. Nonetheless, the shared process of self-reflexive exploration of one's own journey through narrative inquiry offers a pathway for fostering individual and collective leadership that holds relevance for the sector, the community, and the wider region.

\section{Narrative Inquiry}

Narrative inquiry or "the study of the ways humans experience the world" (Connelly and Clandinin 1990) offered particular appeal for this research, and evokes the kind of critical reflexivity that is central to aesthetic understanding (Ladkin 2018, p. 44). 
As social beings, we find meaning and make sense of our own lives and the world we live in through the stories people use, tell, and even live (Bruner 1986; 2004; Giddens 1991; McMullen and Braithwaite 2013). The fact that narrative inquiry has at its core a focus on the study of experience, as it is lived (McMullen and Braithwaite 2013), holds relevance to a wide range of disciplines from anthropology to cultural studies to communication to international relations and diplomacy (Mitchell 1981; Maynes et al. 2008; Daigle 2016). It is a form of inquiry that is familiar to the study of organizational leadership (Jackson and Parry 2018; Komolthiti 2016; Kempster and Stewart 2010; Fleming 2001). But it is less familiar to the study of leadership in a global policy context. Megan Daigle (2016, p. 26) makes this point when she notes that "storytelling presents a challenge to traditional ways of writing, thinking and knowing in the world of international politics." Yet, it is an important challenge - particularly in a world where issues of representation, cultural and linguistic misunderstanding, reciprocity, and power relations loom large. Daigle observes, in addressing this challenge narrative "facilitates an understanding of the way that the international acts at the level of individual lives and bodies - and vice versa."

Qualitative narrative inquiry that allowed participants to write their own narrative addressing their journey through the arts from an individual, national, and regional perspective was pursued. We applied an auto-ethnographic approach whereby participants authored their own story. By engaging with "the storying experience" of ASEAN arts practitioners, we sought to explore and illuminate the perspective of these individuals, all of whom are engaged in artistic and cultural practice in their nation, the region, and the wider world.

As researchers, our role was to ensure that the voices from within the arts and culture sectors of the ASEAN region were heard and to determine whether there is a commonality of discourse. We did not presume to change those individual voices or stories, but to allow them to stand in their original form. However, we were also keen to reveal the collective experience to emerge from their multiple voices. The contents of the narratives were analyzed to form a view of the individual and collective perspectives of this group. We sought to identify, understand, and perhaps interpret the common themes and to map these themes against frames of leadership to reveal the aspirations and inherent weaknesses in the leadership capacity of our group. In doing so, we hoped to bring greater understanding and visibility to the place and relevance of the arts and cultural sectors within the region as a broader landscape; ultimately to "give rise to a different kind of wisdom" (Ladkin 2020, p. 2) which might inform our understanding of leadership.

We undertook this task, admittedly as outsiders to ASEAN ourselves, but as individuals with deep and enduring connections to the Asia Pacific region, and an interest in understanding the interplay between and potential for cultural understanding, advocacy, and diplomacy in a regional context - all themes of contemporary leadership. The significance of this work rests in the development of a culturally attuned model of regional leadership development that is responsive to the inflections of individual political and economic circumstances, sensitive to larger state action, and enabling points of dialogue, communication, and exchange. 


\section{Narrative Themes}

The narrative process allowed participants to share personal stories about their entry into the arts sector, the challenges they have faced in navigating the arts sector and structures of the region, and their sense of connectedness to the larger identity and structures of the region. At each level of narrative discussion common themes emerge. Participant statements are quoted through the next section to give emphasis to these themes.

\section{Reflecting on the Local and Personal}

To begin, the narratives focus on the local and personal story, reflecting unique, individual experiences. However, across the collective, it is possible to identify common themes relating to opportunity, identity, voice, and impact. Taking the first of these themes, opportunity, each of the participants noted the significance of opportunity in bringing them into the arts. For some, the opportunity was structural, promoted through established programs or funding models aimed at fostering the arts. For others it was societal, a result of their community connections and networks. And for others yet, opportunity was symbolic: a "portal between two worlds." Interestingly, opportunity was underpinned by a discernible pattern of curiosity and initiative. As one participant noted, "I put myself in every corner of the art scene and the subject of humanities; arts, literature, history, culture, etc. ... because visual arts gave me [the opportunity] to explore."

\section{Identity}

The significance of identity, in terms belonging and acceptance within a diverse community was the second theme to emerge through the local story. The theme resides within all the narratives implicitly. One participant provided a more explicit description noting the relevance of identity in shaping strategic and societal engagement: "The condition of being an outsider is perhaps the most significant aspect of my identity." The participant continues, "I sought spaces where the grip of ethnic identity was challenged and found it on the stage and in its art galleries. Plays, novels, art works, offered different imaginings of nationhood and identity than the narrow framing of citizenship offered by the state." Going further this description also hints at the symbolic significance of identity in the arts "... in the local arts scene, across the language divides, I have seen acceptance of and advocacy for diversity - ethnic, class, gender, sexuality, abilities." The theme resonates not only on the personal level but in the community, the nation, and across the region.

\section{Voice}

The unique capacity to have and to give voice also emerged. For some, voice in the arts related to an ability to give recognition to "stories of hard work, boldness, experimentation, exploration and transformation" symbolizing not just the emergence of a new generation of artists but also the emergence of a new nation. 
Continuing on this theme some saw the arts as an important vehicle for bringing multiple voices into political discourse. One participant reflected on the fact that at the societal level "the arts community was united in the belief that questions must always be asked." Whether it was "... through music, film, visual art, poetry, theatre, we were able to raise probing questions and engage in active citizenship."

For another bringing the voices of others to the fore of the personal narrative revealed an inherent discomfort with drawing attention to that participant's own singular voice ahead of others. The narrative retold the stories of others, particularly those encountered in the field as a way to navigate these tensions. This issue of voice as representation is a familiar one - particularly within ASEAN, a region of vast diversity. As the well-known scholar of Southeast Asia, Farish Noor prompted: who are any of us to speak for anyone beyond ourselves? ${ }^{3}$ Voice and representation appear at both the intrinsically local and widely strategic levels of discussion. It was also noted by this participant that some within the region remain marginalized or invisible to the mainstream conversation. By bringing their voices to the fore, the participant mirrors the objective of this project, thereby breaking through in a discourse where the voices of government or the political elite tend to dominate.

\section{Impact}

Finally, the theme of impact emerges in discussion, described by one as the ability to "gently nudge the boundaries of our students' minds, to encourage them to handle ambiguity and uncertainty in meaning-making and to develop some sort of empathetic imagination for others and for their world." It is an organic interaction, whereby: "in observing each other, we catch glimpses of alternative ways of being that we might not have been able to envision if we stayed narrowly within the frame of our own experiences." For one participant, the desire to have impact is strong: "I' $m$ in the arts because I believe in its power to effect change, to speak where other channels are closed off, to inscribe multiplicity and difference where power seeks to flatten and homogenize." For another, impact is aligned to the responsibility for enabling - through teaching and mentoring - the next generation of practitioners, bringing with it the opportunity to inspire the next generation. One participant talked of imbuing the sense of "responsibility to my students to have the true understanding of theatre arts, have a creative mind and full of imagination, have an excellent skill to deliver ideas, and have the right attitude as a human being."

\section{Reflecting on the National}

When observing the patterns and themes to emerge beyond the personal or local, the narratives shift toward themes that hold relevance for the nation: these include the themes of tradition and memory; experimentation, exploration, and innovation;

\footnotetext{
${ }^{3}$ Dr. Farish Noor took part in a workshop discussion with the participants hosted by The Asia Europe Foundation in Singapore in 2017.
} 
and advocacy through the arts. Here themes take on a national flavor highlighting points of similarity and difference embedded across the nations of Southeast Asia.

\section{Tradition and Memory}

For all the participants, the sense that the past, embodied through tradition is embedded and visible in the present and the future provided a clear point of commonality. Yet these temporal dimensions are experienced and emphasized differently depending on the particular national experience and memory. For our Cambodian participant, the past is inescapable. The reaffirmation of temporal connections reveals a much deeper craving to overcome the disruptive and destructive effect of the genocide which occurred under Khmer rule in the 1970s. Cambodia's artistic community was decimated through genocide, and the stories and traditions passed through artistic and cultural practice halted. As our Cambodian participant attested the legacy of genocide has meant that today, Cambodia's arts practitioners are deeply aware of the "sense of urgency for reviving and preserving the traditional heritage."

The Vietnamese participant emphasizes a different view on the inescapable link between art, colonization, and the evolution of a Vietnamese nation. Indeed, the beginnings of Vietnamese modern art are found in the establishment of the French fine arts institution, l'Ecole Superieure des Beaux Arts, later becoming the Hanoi College of Fine Arts, which held responsibility for educating students from across French Indochina (Vietnam, Cambodia, and Laos), in the French traditions of modern art - an influence that remains visible today. And yet art, alongside language, also played a powerful role as one of the tools of the Vietnamese revolution, "linked to the higher goal of liberation" in Vietnam's struggle against its colonial master. Later again, the same political and ideological factors that drove artistic practice as an underpinning of Vietnam's revolutionary movement worked as a feature of the state to undermine and stifle it, whereby the artistic scene became "scarce, monotonous, and politically tamed."

Similarly, the past holds a similar significance in the themes and conversations borne out across Singapore's contemporary arts and cultural landscape. In part, our participant suggests because the "historical narrative is so contested" whereby the markers of colonialism and independence both define and obscure the narrative of the nation's past. Through their art, artists can interrogate and explore what exists in the contested spaces of history, beyond the political markers and agendas. But as the participant observes in a state bound by rules, "such exploration is not always easy or even possible."

\section{Experimentation, Exploration, Innovation}

From the interplay between the past and memory emerge aspirations from each of the participants to contribute to contemporary ideas that connect the present and the future. Our participants are all closely attuned to the need to strike a delicate balance between respecting, understanding, and learning from past traditions, and moving forward through growth, learning, and innovation. For example, the 
Laotian participant refers optimistically to himself as a part of the new generation of contemporary art and artists. Such a trajectory is essential, not only on the individual level, encouraging the development of artistic form and career opportunities, but also for the nation, contributing to the further opening up of Laos to the outside world.

For others, the trajectory is less straightforward. While our Cambodian participant considers it vital that the country's new generation of artists understand and respect the classical traditions in which they were trained, it is equally important that they are not bound by them. For that participant, there is a need for new artists to experiment, explore, and produce fresh arts practices, to "discover further artistic possibilities" and "actively and courageously" make their mark on "the social and cultural canvas" of Cambodia. To this end, it is a call for artists to lead and advocate for social and cultural change.

Such comments are marked by the duality of caution and optimism. Caution on the one hand, because in Cambodia, as in other countries within the region, "there is also a deeply embedded sense of identity, patriotism, and nationalism" imposed as part of the nation-building agenda. For the arts practitioner, this raises concerns that official cultural policy and its resultant emphasis on traditional cultural practice imbued with the sentiments and interests of the nation-state may be at odds with or at least limit the extent to which authentic artistic creativity and innovation can occur. A further danger remained that new practices would extend so far beyond what was known, that they would either pose a "threat to the continuation of traditional culture" or no longer be "recognizable by the audience as Cambodian." On the other hand, this participant offers optimism, because artistic exploration and experimentation provides a bridge for modern Cambodia and Cambodians in the wider region and world. Despite the "raised eyebrows" from "older artists and masters" these new practices are not an abandonment of tradition, but reflective of the artist's transformative journey through which the nation might also find the potential for transformation.

For all our participants, there appears to be a "tug of war between traditions and contemporary practice and creativity in the arts," revealing deeper tensions about expressions and representations of the national cultural identity, which is not static or controlled, but subject to dynamic forces of change. Preserving the relevance of tradition in the contemporary is neither a simple nor always a possible prospect. The point was made by the Filipino participant, who reminds us through the story of the "old woman who was weaving her funerary blanket" that the real concern about "the traditional slowly dying," remains, as those last remaining few that engage in the practice also die.

While some of our participants are at the forefront of experimentation and innovation in their practice, others see their role in enabling it. One participant describes her role as "the gardener, tending to this tree and that, not without 
contentment." ${ }^{\prime 4}$ It is a role that seeks to cultivate opportunities for artistic practice to generate new conversations. The participant observes that "more and more artists are discussing history or anchor their artwork in alternative findings of history." It is this new sense of exploration that enables artistic/cultural producers to identify new works, to agree to build things together, and to "engage themselves and others in a larger, much needed discourse" on the contemporary nation. Importantly, it is creative interactions nurtured by an emerging arts scene that offers significant new opportunities for learning, exchange, and collaboration across Southeast Asia.

\section{Advocacy}

Working within the arts sector also involves a degree of advocacy. In some cases, that means working within and across established structures and policies to promote and protect the interests of the diverse communities living within the bounds of the nation-state. In telling the stories of the Filipina women weavers and tattoo artists, one participant reaffirms the place for groups and institutions that recognize and support the continued practice of indigenous arts - including through the organization of the artists, product development, access to training and development, and sourcing of materials and equipment. The participant notes the important, though sometimes informal or ad hoc networks linking individuals and locales to each other and to a wider national community and market.

While recognizing that there is "a system of coordination among cultural agencies," the participant highlights the significance of established programs that support and help sustain traditional and contemporary arts. From this perspective, all participants recognized the national effort directed toward the preservation and recognition of traditional arts within their respective nations. Some noted that the national effort was further strengthened through well-recognized international programs, awards, and processes, such as UNESCO's Masterpieces of the Oral and Intangible Heritage of Humanity. Yet while such programs and awards offer significant prestige and status to the nation-building project, there was also a sense of suspicion among participants that the very same programs might also fuel nationalistic tendencies, engendering rivalry and animosity between peoples, communities, and states of the region rather than contributing to understanding, respect, and trust. Their skepticism was palpable and signaled a reluctance to engage with the machinery of the state too closely.

Arts practitioners are often cognizant of the various ways that the interests of power structures within the nation-state impact more broadly on parts of society. For example, as one participant observes, the "life and culture of the people, not only

\footnotetext{
${ }^{4}$ Here too we find a connection between the role of the arts practitioner the diplomat - the latter often referred to as a "constant gardener." Donna Oglesby (2017) reminds diplomacy involves the caretaking "of an instinctual art wherein day-in day-out toil takes vision, commitment, technique, the right cultural material and time. To succeed they must cultivate feeling, because the personal is the ground in which the seeds they cast either germinate or fall fallow." It is an enduring metaphor that recalls ancient philosophy of Socrates and Plato. Voltaire (1751) too famously urged that we must cultivate our gardens.
} 
the indigenous communities in the highland and coastal areas, but also in the lowland" are affected by larger interests associated with rivalry and conflict, exploitation, mining, and commercialization. There exists then a call to "continue the advocacy - to be the voice, or deliver a platform and a venue for these people to be heard and participate in providing a better community [that might] grow, thrive and prosper."

The same participant raises the theme of struggle and resistance in ways that might hold meaning not just from a national perspective but also for the region. This time, she uses these themes implicitly firstly to remind us that all humans regardless their diversity are connected through art and culture in the "celebration of life and its struggles," and secondly to challenge us to ensure that "the language, the politics and the engagement of art continue to become [and remain] a part of our daily lives." Resistance, as she notes, then becomes a "struggle of memory against forgetting."

Others within the project take a more cautious approach to the role and relevance of national cultural policy - whereby art is merely the instrument for economic gain. For some, the "development model where growth is the end game for cultural producers," where "funding is tied to production and presentation" and where "there is an expectation for arts events to hit ever-growing audience targets" reflect a worrying trend of national policy. It is a model that seeks out "mechanisms of control" in the form of funding structures, licensing requirements, ratings, or censorship; all of which work to constrain rather than promote artistic experimentation, exploration, and provocation; and "hamper artistic freedom and growth."

Themes of experimentation and exploration and a desire for arts to "remain responsive, open to improvisation and to avoid bureaucratic calcification" dominate the philosophy of the arts manager. These themes, familiar across the narratives, sit uncomfortably with the perspective of state involvement and control over the sector - driven by the "prevalent social, political and economic agendas embedded within the ... cultural policy of the time."

The constraints and controls have in the view of one participant led to an era of "truthiness" where authenticity is contrived, and opinions reproduced and reaffirmed to conform with the dominant discourse. The net result, this participant suggests, "is a polarized world, where segments of society can cling to increasingly opposing positions on issues" and where the common space between those segments continues to diminish. Optimism about the arts providing that "common space, where issues could play out and discourse could happen" falters as "the arts have, increasingly, become yet another battleground and place of division." But yet as participants note, "the arts and cultural sector needs to find a way to have conversations."

For several participants, responsibility of advocacy for and through the arts becomes a kind of "public service." The view emerged that "art has a key role in encouraging reflexivity and further dialogue," especially in airing difficult or taboo topics, critiquing societal systems and structures, and articulating alternatives. "Art, plays an important role in articulating these possibilities and alternatives in how else the world can be." 


\section{Reflecting on the Regional}

Participant narratives reveal broad similarities in the way that participants are connected to and engage with their regional identity. More specifically, some engaged positively with their Southeast Asian identity, yet resisted any notion of an ASEAN identity, noting a striking disconnect from the formal, political - even elite - construct of ASEAN. When prompted, participants reflected on the limited impact, on a personal level and as practitioners within the arts and cultural sectors of ASEAN's member nations. It becomes clear through their reflections, while they may identify as Southeast Asian, that they do not know much about the people and nations of ASEAN. At the people-to-people level, one might conclude that ASEAN does not know itself.

Furthermore, the narratives hone in on undercurrents of national rivalry and tension playing out within the respective arts and cultural sectors of the region. Whether related to cultural rivalries and even hostilities between Thailand and Cambodia, or Malaysia and Singapore, such issues contribute little to a mindset that is resistant to regionalism. The narrative reflections prompted several participants to highlight the opportunity that exists for ASEAN to consider, at political and community levels, how to better recognize and celebrate the traditional and contemporary arts and cultural practices that exist not within the member nations per se but within and across the region as a shared asset and resource of the people.

\section{Connectivity and Networks}

To this end, all the narratives all speak in various ways about the aspiration and optimism that ASEAN might offer to them, particularly as a platform for connectivity and building networks. For some, ASEAN represents an opportunity to connect to the outside world, to engage in openness and advancement. For others, ASEAN might enable connections and collaborations with peers who are otherwise unknown. As one participant suggested the ASEAN institution might usefully work to "intensify a sense of translocality."

While reflecting on connections to the region, another participant returned to the facilitative role of ASEAN "focused on the plight of the traditional weavers in the region." It is an example that reminds us that the commonalities that exist in the art form and tradition, alongside the issues that are faced by those who practice it, hold significance across the region, particularly "in the face of globalization." Thus, ASEAN plays an important role as a forum for bringing individual practitioners together in dialogue about shared issues and interests. Furthermore, ASEAN must enable more than mere artistic appreciation, and instead allow artists to bring their collective voice to the fore on issues of significance to the region through artistic practice. One participant asks: "can the arts be a bridge, not just to cross for short-term individual goals but to experience the long-term collective beauty and productivity of cultural diversity to create shared narratives?" 


\section{A Multi-frame View of Leadership}

The themes emerging from the narrative process offer further insights for understanding and developing the leadership potential of arts practitioners operating within a complex global world. They reinforce the complex view of contemporary leadership, whereby leaders must operate within multiple contexts and across formal and informal structures, engaging diverse audiences in the process. Mapping the narrative themes against Bolman and Deal's $(2003,2014)$ multi-frame leadership model ${ }^{5}$ provides general insights into the capacity of arts practitioners to lead within the political, structural, social, and symbolic spheres. Arts practitioners tend to engage, both consciously and intuitively across each of the frames; an approach which, in our study of Southeast Asian arts practitioners, demands and enables understanding of and engagement with issues at the local, national, and regional perspectives. And yet inherent weaknesses also come into view.

\section{Leadership in the Political Frame}

Political leadership operates at a strategic level offering vision and direction. Bolman and Deal (2003, p. 359) suggest that successful political leaders "map the political terrain by thinking carefully about the key players, their interests and their power." These leaders also understand that "influence begins with an understanding of others' concerns and interests." Political leadership requires a self-awareness of who you are and what you stand for as a community, and an ability to convey that story to your constituency, and external audiences as you move forward. Notably, the participants within our study do not view themselves as political leaders, but rather as individuals with the collective of the arts, representing different aspects of that sector and community. They do hold positions of authority within their communities, are aware of and attuned to local and national political dynamics impacting on their sector, and know how to interact with individual governments or funding agencies. However, at an individual level they have not fully understood how to strengthen their individual and collective agendas in a political and strategic frame.

The themes to emerge from the collective narrative reveal a problematic tension. On the one hand, they highlight an acute wariness among arts practitioners of political institutions and processes, and a lack of trust in political motivations. This is understandable in a region where cultural policy may be wielded in a heavy-handed fashion. Yet on the other hand, practitioners see themselves and their practice as playing a significant role in advocacy to improve outcomes within

\footnotetext{
${ }^{5}$ Bolman and Deal (2003) identify the four frames of organizational leadership in the following way and order: (i) structural leadership; (ii) human resource leadership; (iii) political leadership; and (iv) symbolic leadership. For the purpose of this study we have adapted the order to reflect a logic more suited to leaders and leadership in a global context. Similarly, we have renamed human resource leadership to social leadership to reflect a community-oriented approach.
} 
their local communities, to broaden horizons and challenge established thought. The advocacy role appears deeply embedded within their identity as individuals and as a sector.

At the same time, despite their worldliness, the self-knowledge of our participants appeared confined, bounded by these localized perspectives. This lack of knowledge of each other's context within Southeast Asia (i.e., not knowing themselves) obscured the potential for wider strategic thinking, and deflected the need to selfinitiate, further compounding their disconnect from a strategic political leadership frame. And, this was mirrored through their behaviors. During the early stages of our study, the participants were reluctant, if not unable to conceive of the supragovernmental constructs and causes of the wider region.

The process of developing and sharing narratives helped to bridge this disconnect, opening the way for more purposeful discussion, and highlighting common experiences, concerns, and challenges. It provided the participants an opportunity to engage with a wider political frame and develop their confidence and advocacy skills from a sectoral rather than a national perspective, and within a safe platform of exchange and trust building, in a region where distrust between nations remains.

\section{Leadership in the Structural Frame}

Structural leadership flows from and is the mechanism by which institutions seek to implement the vision and direction of strategic leadership. Effective structural leadership brings architecture and coordination to an otherwise diffuse network of people, activities, and institutions. Structural leaders are social architects who apply analytical and design skills to diagnose problems and develop solutions. While structure is important, it tends not to be confined by rigidity, and effective structural leaders find ways to experiment, innovate, and adapt. Our participants exhibited tendencies toward successful structural leadership, particularly within their own sectors, where the urge to coordinate and program, with an emphasis on experimentation was strong. Yet it became clear that structural leadership abilities of these participants are stymied by an otherwise deep wariness of structures and institutions, both at the national level - more notably when it came to discussion of ASEAN - as well as at the regional level. Indeed, the participants overwhelmingly resisted the language and the architecture of ASEAN, preferring instead to talk of informal connections they might foster as Southeast Asians.

This was a particular point of interest for us, particularly given the investment made by ASEAN in recent years in cultivating a socio-cultural community based on the role of arts and culture. The narratives suggest that the structural leadership deficit exists at multi-levels. Firstly, and despite increased investment in communitybuilding, ASEAN's leadership has been unable to break through the barriers of bureaucracy to gain relevance and build discourse within communities. For example, even though it was launched in 2016, the ASEAN Strategy for Arts and Culture is not well known, understood, or accessed by many practitioners across the sector. Secondly, from the arts practitioner perspective, there emerges a reluctance to 
engage with ASEAN's regional architecture. The experiences of the arts sector would suggest that such wariness is warranted. Nations across Southeast Asia have endured and continue to witness the exploitation, control, or oppression of artists and arts practitioners for political ends. Indeed, the enduring argument from the arts sector suggests that artistic impulse transcends the state. However, the reality for today's arts practitioners requires more cogent engagement with structure, and the development of a language and process for more appropriately dealing with structures of the state, and in the case of ASEAN, of the supra-state. Where policies exist that might enable improved engagement and understanding between and within nations through the arts, then arts practitioners must become sophisticated in accessing those policies and negotiating the terms. Navigating the structures is essential to realizing opportunity, and bringing the deep aspirations for voice and impact sought by each of our participants, to life.

\section{Leadership in the Social Frame}

The social leadership frame is adapted here from Bolman and Deal's (2003) "human resource leadership." It reflects the community rather than organizational focus of our arts practitioners, but the qualities and skills associated with this frame remain the same. Effective social leaders use skill and artistry in helping people to accomplish extraordinary results; they empower others to engage. Successful social leadership extends from an authentic connection to audiences at grassroots - to understand, engage, and influence through interaction based on expression and dialogue.

Arts practitioners excel in this dimension of leadership: understanding audience, significance of venue, and need to connect with meaning in a community setting. They also bring a nuanced view to their social leadership responsibility, recognizing the significance of identity and belonging, particularly at the local level and the potential role for the arts in bringing those on the outside in. Drawing on their national perspectives, these practitioners are highly attuned to the deep tensions that exist between tradition and modernity, and yet keen to continue to nudge the boundaries of innovation and experimentation (also a trait for successful structural leadership). From a wider even regional perspective they place emphasis on the importance of connectivity as a means of bringing commonalities to the fore, while also allowing for challenges and issues to be aired.

\section{Leadership in the Symbolic Frame}

Symbols give meaning. They play a critical role in translating strategic vision and structural processes into expressions that make sense within the shared lived experience, values, and beliefs of a community. Symbolic leaders "interpret and reinterpret experience" (Bolman and Deal 2003, p. 360). They work on the basis that reality is socially constructed, where "meaning is created and maintained through behaviour 
and at the same time influences behaviour" (Winkler 2010). Effective symbolic leadership draw on symbols, in the form of material objects, behavior or language to capture attention, to inspire and even transform followers. The effectiveness of symbolic leadership resides in its authenticity.

The participants in our study demonstrated an intuitive understanding of symbolic leadership. Unsurprising given their practice, yet illuminating for those outside it. At the local level, it sits with the notion of identity moving through portals between worlds, and the place and resonance of the voice as a symbol of chance and impact generated through glimpses of alternative ways of being. Viewed from the nation level, symbolism emerged from national tragedies, and lay in the responsibility of arts practitioners to encourage both revival and preservation of the past, in order to account for, remember, and reimagine what has been lost and what survives within a community. When speaking about their region, the participants called for connectivity that might intensify their sense of "translocality" that went beyond depictions of ASEAN as political leaders holding hands but engendered a real sense of knowing and understanding.

\section{Implications of the Study}

Our research brought together arts practitioners from across this region to consider issues relating to leadership in the Asia-Pacific region, and within the regional construct of ASEAN. For this project, narrative inquiry offered us the chance to develop a process that is "alive": an informed engagement and representation of the cultural sector's role in the construction of the ASEAN region. By engaging with "the storying experience" of these arts practitioners, we sought to explore and illuminate the potential for nontraditional leaders to operate in their community, nation, and region. The aim was to engage in an evocative process, through which subjective voice might present a layered picture, which developed over time would provide insights into the leadership potential and development needs of arts practitioners.

What emerged through the stories was a complex and textured account of how arts practitioners consider and engage intuitively with leadership opportunities at multi-levels: the local, national, and regional, and in multidimensions: strategic, structural, social, and symbolic. There is an unevenness in this engagement, and deficiencies are revealed through the process of narrative, particularly when considering the strategic and structural leadership tendencies. For example, the resistance exhibited by the arts practitioners in this study to formal political structures and language opens potential leadership gaps. It is a natural resistance, particularly when discussed in the context of their individual and collective national experiences. Yet without an awareness and an ability to engage with strategic or structural leadership frames, arts practitioners and the sector as a whole may never be invited to the table, and leadership in culture will only ever be a footnote.

On the other hand, through this process, the particular strengths of arts practitioners as social and symbolic leaders came to light. Their instinctive ability 
to connect at a very human level, to interpret experience and to empower audiences, offers significance for leadership studies and development. Yet these leadership traits appear, in the context of Southeast Asia, to occur in localized spaces and networks. Once again, the disconnect emerges between the local and the region. The challenge facing political leaders, including those within ASEAN regional structure, is to enable diverse local perspectives and cultural inflection at the local levels, rather than pursue a homogenized outcome.

ASEAN leaders and officials have engaged in intense discourse about an ASEAN regional identity, particularly since the 50th anniversary of the institution itself. The creation of ASEAN's Socio-Cultural Community, as part of ASEAN's broader community building efforts from 2015, fed into this discourse and is developed through other initiatives including the ASEAN Socio-Cultural Community Blueprint 2025. Cultural cooperation is lauded through the Blueprint as a vehicle for establishing "a dynamic and harmonious community...aware and proud of its identity heritage and culture" (ASEAN Secretariat 2016b, p. 3). And yet, the leadership role for arts practitioners within the regional context remains elusive. Arts practitioners themselves remain disconnected from the political correctness and formality of ASEAN's community building approaches, and skeptical of the deeper political intent. For them, the aspiration of an ASEAN community is far from being met. It is a long-standing issue, as former ASEAN Secretary General, Severino (2007, p. 369) observes that "the trouble, in the ASEAN context, is that these "people concerns' are functions and responsibilities of individual states." The nation-state which looms large in the ASEAN psyche gets in the way, and it would appear of broader community-mindedness.

A deeper disconnect to emerge through the narratives is the disconnect that arts practitioners feel at times from each other within the imagined social construct of Southeast Asia - upon which the more formal structures of ASEAN have been constructed. Farish Noor (2017) proposes this view, noting that Southeast Asia remains an unknown from within, and calling for "a recognition of the Others within, and the acceptance of the fact that these Others are always our Others - the constitutive Other that makes us what we are." If there is to be a leadership role for arts practitioners in the ASEAN context, surely it might be developed to address these internal divides across multiple identities, and to deliver awareness, understanding, and perhaps also tolerance for the "constitutive other."

\section{Conclusion}

Through this research the intention was to develop a rich framework for leadership capacity building; as the participants became owners of the thematic journey, embodiments of their practice and narrators of their own stories, at a confluence of cultural and political discourse. The narrative approach applied through this study underscores the aesthetic dimension of leadership and provides a novel framework for the individual and collective to actively and critically engage that dimension. 
The study also reinforces the connection between leadership and the arts. Yet with a deliberate emphasis on arts practitioners, it brings attention to the leadership from and within the arts sector. We discovered through this process that arts practitioners, generally at ease dealing in their social circles and sectors, remain ambivalent about their role in connecting through political mechanisms and structures. On the one hand, it appears that such ambivalence emerges through an inward focus on the self, while on the other it reflects intuitive skepticism of the political state - whether operating at the national or regional level.

Our focus on arts practitioners from Southeast Asia therefore has further implications for the ASEAN regional framework. Ultimately, the development of leadership capacity that enables and empowers arts practitioners within the political domain on a sustained basis is required if arts practitioners are to play a more significant role in regional community building. At the same time, processes that enable arts practitioners to develop their voice and deliver sustained impact - beyond the personal, across identities and societies, while allowing for cultural inflection may provide opportunities for much-needed forms of regional awareness and understanding generated from within.

\section{Cross-References}

The Role of Aesthetics in Ethical Action

\section{References}

Asbjörnson K (2007) Making the connection between art and leadership. Issues Observ 27(4):22-24

ASEAN Secretariat (2016a) Strategic plan for culture and the arts 2016-2020. ASEAN Secretariat, Jakarta

ASEAN Secretariat (2016b) ASEAN Socio-Cultural Community Blueprint 2025. ASEAN Secretariat, Jakarta

Beardsley MC (1991) Aesthetics from classical Greece to the present, 8th edn. Macmillan, New York

Bereson R, de Monthoux PG (2017) Special issue editorial: Poetic pragmatism and artful management. Philos Manag 16(3):191-196

Beuchel B, Antunes D (2007) Reflections on executive education: the user and provider perspectives. Acad Manag Learn Educ 6(3):401-411

Blocker HG (2001) Non-Western aesthetics as colonial invention. J Aesthet Educ 35(4):3-13

Bolman LG, Deal TE (2003) Reframing organizations: artistry, choice and leadership, 3rd edn. Jossey-Bass, San Francisco

Bolman LE, Deal TE (2014) How Great Leaders Think: The Art of Reframing, Jossey-Bass: San Fransisco

Bruner JS (1986) Actual minds, possible worlds. Harvard University Press, Cambridge

Bruner JS (2004) Life as narrative. Soc Res 71(3):691-710

Connelly FM, Clandinin D (1990) Stories of experience and narrative inquiry. Educ Res 19(5):2-14

Daigle M (2016) Writing the lives of others: storytelling and international politics. Millennium J Int Stud 45(1):25-42 
Flemming D (2001) Narrative leadership: using the powers of story. Strateg Leadersh 29(4):34-36

Garvin DA (2007) Teaching executives and teaching MBAs: reflections on the case method. Acad Manag Learn Educ 6(3):364-374

Giddens A (1991) Modernity and self-identity: self and society in the late modern age. Stanford University Press, Stanford

Guillet de Monthoux P (2004) The art firm: aesthetic management and metaphysical marketing. Stanford University Press, Stanford

Houde J (2007) Analogically situated experiences: creating insight through novel contexts. Acad Manag Learn Educ 6(3):321-331

Jackson B, Parry K (2018) Studying leadership. Sage, Los Angeles

Kempster S, Stewart J (2010) Becoming a leader: a co-produced, auto-ethnographic exploration of situated learning of leadership practice. Manag Learn 41(2):205-219

Kets de Vries M, Korotov K (2007) Creating transformational executive education programs. Acad Manag Learn Educ 6(3):375-387

Koivunen N (2003) Leadership in symphony orchestras: discursive and aesthetic practices. Tampere University Press, Finland

Komolthiti M (2016) Leadership journeys: a narrative research study exploring women school superintendent's meaning-making of leadership development experiences. Northeastern University, Boston

Ladkin D (2018) The aesthetic and its relationship to business ethics: philosophical underpinnings and implications for future research. J Bus Ethics 147:35-51

Ladkin D (2020) The Role of Aesthetics in Ethical Action. In: Neesham C., Segal S. (eds) Handbook of Philosophy of Management. Handbooks in Philosophy. Springer, Cham. https:// doi.org/10.1007/978-3-319-48352-8_28-1

Ladkin D, Taylor S (2010) Leadership as art: variations on a theme. Leadership 6(3):235-241

Maynes MJ, Pierce JL, Laslett B (2008) Telling stories: the use of personal narratives in the social sciences and history. Cornell University Press, London

McMullen C, Braithwaite I (2013) Narrative inquiry and the study of collaborative branding activity. Electron J Bus Res Methods 11(2):92-104

Mitchell WJT (1981) On narrative. University of Chicago Press, Chicago

Noor FA (2017) Where do we begin? Reclaiming and reviving Southeast Asia's shared histories and geographies. In: Baviera A, Maramis L (eds) Building ASEAN community: political, economic and socio-cultural reflections. Jakarta, Economic Institute for ASEAN and East Asia

Oglesby DM (2017) Sowing the seeds of diplomacy on hard American ground. Hague J Dipl 12(4):383-315

Pick J (2009) The aesthetic contract. Merrill Press, Kenmore

Severino RC (2007) Southeast Asia: in search of an ASEAN community. Institute of Southeast Asian Studies, Singapore

Sutherland I (2012) Arts based methods in leadership development: affording aesthetic workspaces, reflexivity, and memories with momentum. Manag Learn 44(1):25-43

Voltaire (1781) The Age of Louis XIV.: To which is Added, an Abstract of the Age of Louis XV. United Kingdom: Fielding and Walker

Winkler I (2010) Contemporary leadership theories. Contributions to Management Science, Berlin 